\title{
Possíveis Limites do Mapeamento Sistemático: Uma Visão de Pesquisadores de Engenharia de Requisitos
}

\author{
Roxana L. Q. Portugal, Ana Maria da Mota Moura, Romeu F. de Oliveira, \\ Julio Cesar Sampaio do Prado Leite \\ Departamento de Informática, PUC-Rio. \\ \{rportugal, amoura, rferreira,julio\} einf.puc-rio.br
}

\begin{abstract}
No início de uma pesquisa, é preciso verificar o estado da arte. Nesse sentido, diversas estratégias são utilizadas, uma delas é o mapeamento sistemático. No entanto, é possível que esta estratégia limite as possibilidades de busca, pois o mapeamento sistemático deixa de examinar: os principais periódicos, as principiais conferências, os principais pesquisadores, assim como teses ou dissertações. Além disso, pode deixar de explorar áreas afins. Esse vídeo mostra um caso onde, três pesquisadores escolhem diferentes maneira de explorar a literatura, tomando como base às 5 perguntas definidas no mapeamento sistemático de um dos autores. A pergunta principal desse mapeamento é: Como promover Acessibilidade Web em Tempo de Execução? Esse vídeo mostra a literatura selecionada por cada pesquisador, os métodos usados, assim como a discussão dos resultados.
\end{abstract}

Link: https://vimeo.com/288008086

Keywords: Mapeamento Sistemático, Engenharia de Requisitos, Accessibilidade Web.

\section{Acknowledgement}

Roxana L. Q. Portugal e Romeu F. de Oliveira agradecem o apoio da Capes. Julio Cesar Sampaio do Prado Leite agradece o apoio de Cnpq e Faperj. 